serve the ABFM on the Examination Committee and the MC-FP Committee.

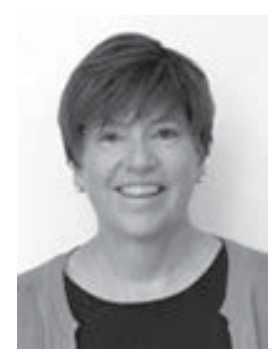

Colleen Conry, MD, is the Senior Vice-President for Quality and Clinical Affairs in the Department of Family Medicine at the University of Colorado. She previously served as Vice-Chair of Graduate Medical Education at the University of Colorado. Dr. Conry will serve the ABFM on the Research \& Development Committee and the Communications/ Publications Committee. She will also serve as a representative to the Residency Review Committee (RRC).

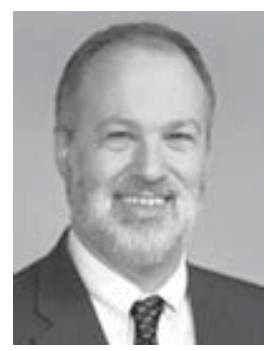

Robert J. Ronis, MD, MPH, is the Douglas Danford Bond Professor and Chairman for the Department of Psychiatry, and the Associate Director for the Neurological Institute and Psychiatrist-in-Chief for the University Hospitals Case Medical Center at Case Western University School of Medicine.

Dr. Ronis will serve the ABFM on the Credentials Committee and the Communications/Publications Committee.

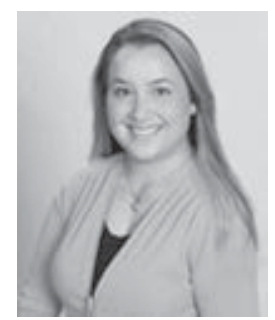

Melissa Thomason has been a Vidant Health Patient and Family Advisor since 2011 and has participated as a Patient Advocate and Speaker throughout the country. She currently serves on North Carolina Quality Center's Patient and Family Advisory Council,

National Quality Forum's Surgery Standing Committee and North Carolina Institute of Medicine's Patient and Family Engagement Taskforce. Ms. Thomason will serve the ABFM on the Credentials Committee and the Communication/Publications Committee.

The remaining current members of the Board are: Elizabeth G. Baxley, MD of Greenville, North Carolina, Laura M. Brooks, MD of Lynchburg, Virginia Montgomery Douglas, MD of Valhalla, New York; Joseph Gravel, Jr. MD of North Reading, Massachusetts; Carlos Roberto Jaén, MD of San Antonio, Texas; Jerry Kruse, MD, MSPH of Springfield, Illinois; Lorna Lynn, MD of Wynnewood, Pennsylvania; David E. Mercer, MD of Omaha, Nebraska; Marcia J. Nielsen, $\mathrm{PhD}$ of Washington, $\mathrm{DC}_{i}$ and David Soper, MD of Mt. Pleasant, South Carolina.

\section{THIS YEAR'S CONFERENCE ON PRACTICE IMPROVEMENT HIGHLIGHTS INNOVATIONS FOR PRACTICE REDESIGN}

As the nation looks to family medicine to serve as the foundation of a transformed health care system, practices are struggling to respond to regulatory and payer expectations for improved outcomes and patient expectations for enhanced access to care and care coordination.

In December, the Conference on Practice Improvement will tackle these issues head on. Providers, researchers, educators, and practice staff will provide examples and strategies for practice redesign. Some specific highlights are mentioned below.

\section{Primary Care Office of the Future}

This year's conference will feature hands-on simulation of new practice designs and technology for primary care transformation. Clinical teams will be able to take a guided tour to experience innovative technologies and redesigned environments that facilitate enhanced team communication, patient engagement, and proactive care.

The Connecticut Institute for Primary Care Innovation (CIPCI) is partnering with STFM and innovative companies to demonstrate technology and workflow enhancements for the Primary Care Office of the Future. Originally created by CIPCI, the exhibit will help learners, clinical teams, and policy makers envision the future of primary care, and serve as a launching point for transformation projects.

Thanks go to CIPCI team leaders, Thomas Agresta, $\mathrm{MD}, \mathrm{MBI}_{i}$ Jeri Hepworth, $\mathrm{PhD}_{i}$ and Rachael Ingersol, $\mathrm{MA}$ for their time and commitment in planning and organizing this unique experience.

\section{General Session Speakers}

Melissa Gerdes, MD, chief medical officer of Outpatient Services and Accountable Care Organization Strategy (ACOs) for Methodist Health System will address ACOs, specifically how practices need to transform to participate in value-based payment, and what it takes to be successful in the new payment environment. Halee Fischer-Wright, MD, president and chief executive officer of Medical Management Group 
Association, will share her expertise as CEO of Medical Management Group Association on the role of leadership and leading change in primary care. Tom Bodenheimer, MD, MPH, director of the Center for Excellence in Primary Care at the University of California, San Francisco and an adjunct professor in the Department of Family and Community Medicine, will speak about resilience for clinical teams in pursuit of the Triple Aim.

\section{Practice Management Boot Camp}

Presenters Scott Fields, MD, MHA, Bruin Rugge, MD, $\mathrm{MPA}_{i}$ Benjamin Cox, MBA, Oregon Health \& Science University; and John Rugge, MD, Hudson Headwaters Health Network will lead an optional workshop for residents, new practicing physicians, and new faculty. Presenters will engage the participants in an active conversation and small-group activities addressing issues such as:

- How to be a good partner in a busy practice

- The role of primary care in accountable care organizations, understanding the importance of visit coding, relative value units, and payment

- What to know prior to signing a first contract; basic financial planning, including employer benefits, loan repayments programs, and planning for the future; and use of data to improve a practice and patients' health.

\section{Family Medicine for America's Health Core Topics Track, Invited Presentations}

The conference will include a track of sessions specific to the 6 core teams of Family Medicine for America's Health (FMAHealth) and how they envision the future of practices. The FMAHealth track will have presentations by core team members on practice, payment, research, technology, workforce, and engagement.

Other invited sessions will feature topics of direct primary care, social determinants of health, meaningful use, medical Spanish, and the changing environment of payment reform.

The Conference on Practice Improvement will be held December 3-6, 2015 at the Intercontinental Hotel in Dallas, Texas. More information is available at http:// www.stfm.org/cpi.

Traci Nolte, CAE

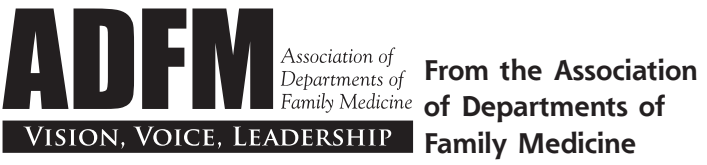

Ann Fam Med 2015;13:494-495. doi: 10.1370/afm.1859.

\section{INFLUENCING STUDENT SPECIALTY CHOICE: THE 4 PILLARS FOR PRIMARY CARE PHYSICIAN WORKFORCE DEVELOPMENT}

Medical students choose a career in family medicine based on the combined influence of many factors. A framework (pipeline, process of medical education, practice transformation, and payment reform) based on the Four Pillars for Primary Care Physician Workforce Development ${ }^{1}$ provides a logical basis to address student interest in family medicine. Individual departments of family medicine (DFMs) have variable influence and ability to affect these pillars and subsequent student career choice. While the 4 pillars may imply equal impact of each factor on specialty choice, this commentary describes the differential influence of each, and opportunities for greatest return on investment to best meet the nation's urgent health care needs.

\section{Pipeline}

The first pillar is the pipeline, through which students demonstrate interest in a medical career and are subsequently selected for admission to medical school. The pipeline should begin no later than secondary school and progress through high school and college. Promoting an interest in family medicine to diverse groups early in the process, and ensuring an ample representation of family physicians on medical school admissions committees helps to enroll students who are more likely to choose careers in primary care and also to serve where needed. ${ }^{2,3}$

\section{Process of Medical Education}

This is the pillar that DFMs can influence most directly to guide student career choice. Engaging faculty who are inspiring, passionate, and who demonstrate the breadth of family medicine are the strongest role models for the discipline of family medicine. Departments should develop active family medicine interest groups (FMIGs) that engage students in the first 2 years of medical school, and support them through their clinical years. FMIGs are an excellent resource for community engagement, professional development, and identity formation. Involving students in longitudinal relationships with patients and transformational educational activities that demonstrate the central role family physi- 